\title{
A Cidade Contemporânea e o Espaço da Criança Interações Sobre a Cidade, a Infância e a Apropriação do Espaço Público
}

\section{Elenise Felzke Schonardie}

Doutora em Ciências Sociais, professora permanente do Programa de Mestrado em Direitos Humanos da Unijuí/Brasil; vinculada à linha de pesquisa "Direitos Humanos, Meio Ambiente e Novos Direitos". Advogada. elenise.schonardie@unijui.edu.br

\section{Ana Lara Tondo}

Mestranda e bolsista/Unijuí do Programa de Mestrado em Direitos Humanos da Universidade Regional do Noroeste do Estado do Rio Grande do Sul/Unijuí/Brasil; vinculada à linha de pesquisa "Direitos Humanos, Relações Internacionais e Equidade". Bacharela em Direito pelo Instituto Cenecista de Ensino Superior de Santo Ângelo (CNEC/lesa).

aana.tondo@gmail.com

\section{RESUMO}

Este artigo apresenta para análise a cidade como espaço, também, da criança, tendo por base a ideia de ambientes lúdicos de acesso público, em especial para esse sujeito em formação, contribuindo para a estruturação e (re) significação da cidadania a partir das experiências vivenciadas nesses lugares. Com base no questionamento "Onde estão as crianças na cidade?", o texto aborda inicialmente a dinâmica da cidade contemporânea com ênfase no papel dos citadinos e os espaços destinados à infância nesse estrutura. Na sequência, analisa a produção do território infantil. A pesquisa teórica utilizou-se do método de abordagem hipotético-dedutivo, por meio do procedimento bibliográfico e interpretação sociológica. E conclui pela importância e adequação da apropriação do espaço público urbano pelas crianças, contribuindo, assim, para a criação de uma cidade, não apenas como ambiente de lutas sociais, históricas e de segregação, mas sim como um espaço comum, compartilhado e igualitário, no qual o ideal igualitário possa ser desenvolvido continuamente.

Palavras-chave: Cidade. Cidadania. Espaços lúdicos urbanos. Infância.

THE CONTEMPORARY CITY AND THE CHILD'S SPACE:

INTERACTIONS ON THE CITY, CHILDHOOD AND THE APPROPRIATION OF THE PUBLIC SPACE

\section{ABSTRACT}

The article presents the city as a space, also, for the child, based on the idea of play spaces for public access, especially for this subject in formation, contributing to the structuring and (re)signification of citizenship from experiences in these environments. Based on the question of "where are the children in the city?", The text initially addresses the dynamics of the contemporary city with an emphasis on the role of city dwellers and spaces for children in the urban structure. In the sequence, it analyzes the production of children's territory. The theoretical research was based on the hypothetical-deductive method, through the bibliographic procedure and sociological interpretation. And, concludes by the importance and appropriateness of the appropriation of the urban public space by the children, thus contributing to the creation of a city, not only as an environment of social struggles, historical and segregation, but as a common space, shared and equality, in which the egalitarian ideal can be developed continuously.

Keywords: City. Citizenship. Urban play spaces. Childhood.

\section{SUMÁRIO}

1 Considerações Iniciais. 2 A Cidade Contemporânea e o Espaço da Infância. 3 Desbravando a Cidade: a produção de espaços infantis. 4 Considerações Finais. 5 Referências. 


\section{Democracia}

\section{Considerações Iniciais}

A temática do artigo é motivada pela necessidade de se estudar as relações entre o indivíduo e o espaço que ele habita. Assim, tem como objetivo questionar a possibilidade de apresentar os espaços públicos urbanos lúdicos às crianças para, quem sabe, uma futura apropriação desses espaços pelos futuros citadinos. Tal objetivo justifica-se em razão da sua constante presença nos espaços de interação social.

Dessa forma, ao considerar as crianças com atores sociais e a cidade como cenário cultural, é indispensável pensar sobre as mudanças estruturais pelas quais a sociedade tem passado, o que redesenha o espaço a partir de novas dinâmicas. Assim, o presente estudo parte de uma premissa básica: Onde estão as crianças? A partir dessa questão, busca-se analisar as dimensões da fruição do espaço público pelas crianças, buscando estabelecer relações entre a infância e a cidade, na criação de infâncias urbanas em um novo hiperespaço, criando uma brecha que irá permitir a diferenciação entre as experiências vivenciadas no ambiente urbano durante a infância que poderão interferir positivamente na apropriação do espaço público na vida adulta.

Disso, o que se extrai é que as diferentes dinâmicas sociais geraram uma nova compreensão dos espaços urbanos, com a criação de espaços padronizados, homogeneizantes, tais como shopping centers, e a crescente separação da sociedade por meio de muros. Examinando, nesse contexto, a relação da criança com a cidade, da legitimação da singularidade da criança surge a necessidade de questionar como se dá essa relação entre as crianças e o espaço urbano, e de que forma elas se apropriam desse espaço, que, em tese, também deveria ser delas.

Assim sendo, o artigo divide-se em dois momentos: inicialmente, busca-se analisar a dinâmica da cidade contemporânea, o papel das pessoas na cidade e o próprio espaço destinado à infância dentro da materialização da hierarquia social no espaço físico da cidade. $\mathrm{Na}$ sequência, o objeto de análise foi a produção do território infantil, encarando a rua como um local que pode ser explorado, ao mesmo tempo em que as crianças tornam-se cada vez mais corporalmente passivas em relação a essa oportunidade, surgindo, então, a necessidade da apropriação do espaço urbano por elas.

\section{A Cidade Contemporânea e o Espaço da Infância}

Para DaMatta (1997), o espaço e o tempo são "invenções sociais" e o espaço urbano acabará sendo demarcado pelo estabelecimento de fronteiras, que separam pedaços de chão. Nesse sentido, as cidades tornam-se um espaço que permite a estabilização das inúmeras possibilidades que circundam a nova ordem social (CASTRO, 1998).

O que se percebe, no entanto, é um distanciamento entre o espaço urbano e uma população ativa que irá consumir e se apropriar desse espaço. "De modo geral, os habitantes das grandes cidades [...] usufruem cada vez menos dos espaços públicos, transformados praticamente em espaços de passagem" (DIAS; FERREIRA, 2015, p. 122). Nesse sentido, as particularidades dos diferentes grupos sociais são ignoradas no planejamento e estruturação das 
cidades, não havendo preocupação em considerar as demandas das crianças, que são encaradas apenas como subprodutos dos pais, completamente invisibilizadas (DIAS; FERREIRA, 2015), nas estruturas urbanas projetadas voltadas ao indivíduo adulto.

Ao se considerar o espaço da criança na cidade, um ponto relevante a ser investigado é a própria construção do espaço urbano: como ele é organizado, distribuído e direcionado, e como eles são (ou não) apropriados pelas pessoas - citadinos - aos quais se destina. Nesse aspecto, o espaço que seria das crianças é apoderado pelo poder, primeiro das classes e depois das instituições representativas da sociedade, e transformado num instrumento de dominação (LIMA, 1989).

Isso pode ser explicado pela construção das cidades voltadas ao indivíduo, em sua singularidade e, não a uma coletividade, permitindo a caracterização do que Bárbara Freitag (2006) irá chamar de "reverso da medalha", que, mais do que favelas, invasões e ocupações clandestinas, escancara a construção de cidades partidas, com o abandono do espaço público, se analisadas pelo seu contexto ecológico e cultural.

Dessa forma, o que se percebe é que as funções do espaço da cidade se transformou, em grande parte, de um espaço público focado nas relações sociais para um ambiente de ausência de qualquer relação social, funcionando apenas como um local de passagem (CRUZ, 1998). "As pessoas, em seu ritmo acelerado, vão ganhando as calçadas, atravessando as ruas e se aglomerando em espaços que vêm sendo cada vez mais organizados [...]" (NASCIMENTO, 2006, p. 785). Além disso, o modelo do "sonho americano" infiltrou-se na realidade brasileira, e seus elementos podem ser identificados em todas as esferas da vida urbana (FREITAG, 2006)

Esses espaços privados, tais como shopping centers e centros comerciais, têm um grande número de adeptos, pois são locais que oferecem conforto, praticidade e segurança, facilitando um verdadeiro culto à vida consumista (FREITAG, 2006). Tais "comodidades" oferecidas por esses espaços, todavia, "têm sua gênese em atividades relacionadas ao consumo e suas metas visam ao lucro" (NASCIMENTO, 2006, p. 785), de tal forma que os citadinos que não possuem condições econômicas favoráveis para contribuir por meio da aquisição de bens e produtos ficam excluídos desses espaços.

Essa questão do consumo guia a atitude de crianças e adolescentes, ${ }^{1}$ inclusive, pois os espaços mais desejados por eles acabam sendo esses locais de consumo, restringindo, cada vez mais, o acesso de crianças pelas cidades e diminuindo sua participação ao mero deslocamento para o shopping, que se torna o único atrativo da cidade para elas (CASTRO, 1998). Todos esses fatores geram a constituição de uma infância urbana não voltada à cidade como local de interação social e comunicação, mas sim em espaços fechados e delimitados, prendendo-a em "bolhas de segurança", o que Teresa Caldeira (2000) vem a chamar de "enclaves fortificados", espaços esses que acabarão por alterar o panorama da cidade, gerando mais segregação, demarcação, isolamento, espaços vazios e a consequente desvalorização do espaço público e aberto da cidade.

No caso de crianças e adolescente que se encontram nas classes economicamente privilegiadas, com certo conforto material, fora da zona de segregação econômico-social. 


\section{Democracia}

Humanos

Simultaneamente, outra consequência surge: as crianças acabam tornando-se dependentes dos pais e desinteressadas em explorar o mundo que as cerca, acarretando uma acentuação da infantilização, causada pelo medo da violência, um medo da própria cidade (DIAS; FERREIRA, 2015), pois os espaços públicos urbanos são percebidos, equivocadamente, como locais perigosos, violentos e não recomendáveis, ao invés de serem considerados como ambientes ricos em diversidade cultural, experiências e vivências coletivas.

Nesse sentido, o desafio consiste em estabelecer e delimitar espaços pedagógicos para as crianças nas cidades. Nascimento (2006) destaca que há grande dificuldade em garantir que o público infantil esteja no centro das pesquisas que envolvam a identificação de ambientes de socialização infantil como microssistemas de participação da criança na cidade.

[...] a exacerbação do individualismo: o indivíduo se apropria cada vez menos dos espaços públicos, considerados como pertencentes ao Estado e, portanto, "exteriores" à sua pessoa e à sua família, no que tange à responsabilidade e ao cuidado. [...]. Em vez da esperada apropriação da cidade, ocorre um processo de "estranhamento", no qual o sujeito se preserva do contato com desconhecidos nos espaços públicos, refugiando-se nos espaços privados (DIAS; FERREIRA, 2015, p. 124).

Essa alteração, do espaço público para o espaço privado, é facilmente observada quando se interroga os adultos: a maioria ainda recorda da própria infância, quando as crianças se encontravam na rua, e, nesse espaço urbano, utilizavam-se de diversas formas de brincar. Tal constatação não deve ser encarada por um viés saudosista, contrário a mudanças, mas sim como uma constatação da transformação pela qual a infância tem passado na contemporaneidade, acompanhando as próprias alterações sociais, que mantêm as crianças afastadas da rua e de outros espaços públicos.

Isso acarreta a perda da noção do espaço público como um local de encontros, de convívio, de vivências, de jogos e brincadeiras, dificultando ainda mais a construção e manutenção de ambientes destinados ao convívio coletivo, ao exercício da cidadania. As cidades vêm se tornando, assim, menos atrativas, com uma notável redução da qualidade do espaço público de lazer, por exemplo.

Em cidades de passagem, de espaços reduzidos, de locais privados e especializados, as praças, parques e espaços de jogos têm perdido seu valor e potência criadora no cotidiano das crianças. Atualmente cede-se importância a espaços que se caracterizam por relações comerciais e de consumo, e por sua inadequação ao público infantil, uma vez que são constituídos por elementos "prontos" e acabados, alguns eletrônicos, com estímulos constantes, o que impossibilita a reelaboração e criação de algo realmente novo. Nesse contexto, a criança passa de produtora de uma realidade própria e criativa a depositária de material previamente elaborado pelo adulto (DIAS; FERREIRA, 2015, p. 125).

Outra consequência dessas mudanças é a diferenciação da apropriação desse espaço pelas classes sociais: enquanto as crianças das classes mais altas estão mais sujeitas aos enclaves fortificados de Caldeira (2000), com restrição e controle da ocupação desses espaços, as crianças das classes mais baixas têm um maior contato com os espaços públicos. Em ambos os casos, todavia, a carência de infraestrutura urbana surge como restrições de acesso ao ambiente popular com qualidade (CALDEIRA, 2000; DIAS; FERREIRA, 2015). 
Por outro lado, idealizar a ocupação do espaço livre urbano pelas crianças torna-se ainda mais difícil quando se observa que, historicamente, mesmo podendo falar, crianças permanecem toda a infância sem ter voz. "Suas demandas são, na melhor das hipóteses, 'filtradas' por pais, educadores, médicos, etc." (DIAS; FERREIRA, 2015, p. 120). Isso acabou levando as crianças a uma situação de invisibilidade, uma vez que é o adulto que escolhe e reproduz o cenário sociocultural de participação infantil, mediado por interesses particulares.

Dessa forma, a identidade da criança foi criada a partir de um processo de exclusão social e confinamento a um espaço social "[...] condicionado e controlado por adultos", o que "produziu o entendimento generalizado da privação do exercício de direitos políticos de participação das crianças como um fato natural" (DIAS; FERREIRA, 2015, p. 121). Isso contribui para a naturalização dos processos de exclusão, seja social, territorial ou econômica.

Isso resultou na visualização das crianças como seres desprovidos de racionalidade própria, fato que, diante de sua imaturidade social, ocasionou a ausência de investimentos em espaços públicos, especialmente espaços infantis, e também de sujeitos com dificuldade de percepção e compreensão do outro que não pertença ao seu status social e econômico.

Apesar disso, curioso é constatar que, mesmo silenciadas, não ouvidas, não tratadas como referências, enfim, não reconhecidas em relação aos espaços públicos, as crianças continuam a existir na cidade e dar significado às experiências vividas (ROCCO, 2015). Assim, elas se despem da sua invisibilidade e tornam-se indivíduos e sujeitos de direitos, mais do que meros objetos de proteção, e ganham autonomia para assumir seu papel como sujeitos ativos, citadinos, com efetiva participação no ambiente urbano.

\section{Desbravando a Cidade: a produção de espaços infantis}

As cidades, desde seus primórdios, passaram por longos processos de transformação, que continuam a ocorrer de maneira ininterrupta. No início do século 20 Zygmunt Bauman (2001) criou a expressão "modernidade líquida" para se referir às atuais relações do que ele chama de era moderna, que são pautadas por constantes trocas entre tempo e espaço, com o esvaziamento dos espaços públicos, expansão do privado, efemeridades e aumento da segregação espacial.

Na cidade, a consequência dessas novas relações é a criação de um novo espaço, antes baseado em lutas sociais, culturais e políticas, agora com predominância de relações sociais de imprevistos e improvisação. Basicamente, um novo espaço de (re)encontros. A cidade deve funcionar como o local da diversidade e exercício da cidadania, uma vez que a interação entre o espaço público e a cidadania são elementos essenciais para se conseguir uma cidade ideal (BORJA, 2005).

Dessa forma, diante da percepção de que é preciso considerar a relação entre o indivíduo e o espaço que ele ocupa, motivou-se a criação de sentimentos de pertença, possibilitando, assim, a compreensão do espaço urbano como um lugar mutável, e a rua como universo próprio, que não pode ser definido por meio de uma fita métrica (DaMATTA, 1997). Nesse sentido, os espaços da cidade devem ser pensados como locais que privilegiem a interação entre os indivíduos, as trocas e convivência pautadas não apenas na tolerância entre os diferentes grupos mas, especialmente, na convivência pacífica centrada em uma perspectiva intercultural e intergeracional. A proposição seria a redução dos conflitos sociais interculturais e intergeracionais, por meio de novos espaços propícios ao exercício da cidadania desde a infância. Como construir espaços adequados para uma "vivência mais possível"? (BORJA, 2005). 


\section{Democracia}

Nesse contexto, um elemento a ser identificado é a necessidade do resgate da cidade como um ambiente plural, de prática de atividades políticas, sociais e culturais, surgindo, assim, a necessidade de se questionar (e resgatar!) a apropriação do espaço urbano pela sua população, para que esses espaços deixem se ser "espaços de ninguém" para se tornarem "espaços de todos". Dessa forma, as crianças tornam-se cidadãs, aprendendo desde cedo que a cidadania não é um acontecimento natural, mas sim um processo de aprendizagem social, que pode ser fortemente enraizada na cultura, na medida em que o indivíduo supera aquela mera condição de "consumidor passivo" e se transforma, verdadeiramente, em um "cidadão" (DIAS; FERREIRA, 2015). Mais além, a forma pela qual se encara a cidade deve extrapolar a mera visão territorial, que segrega social e espacialmente, mas sim visualizar a cidade como um espaço social (SANTOS, 1993).

Esse processo, no entanto, encontra resistência quando a criança tenta superar a racionalidade adultocêntrica e busca se impor na cidade. Explica-se. O lugar para o exercício da cidadania no espaço livre não é apenas um espaço concreto, mas sim um espaço fluido, vivido, subjetivado e, por meio de uma ressignificação, o cidadão consegue transformar qualquer lugar no seu lugar. No caso das crianças, todavia, o interesse por esse espaço é desproporcional e inverso ao idealizado pelos planejadores urbanos, que idealizam espaços produtivos, enquanto que as crianças precisam de espaços que produzem e são produzidos (DIAS; FERREIRA, 2015).

A mudança da sociedade, do movimento da industrialização para a urbanização, acarretou profundas mudanças no modo de vida e do cotidiano das pessoas, o que metamorfoseou a própria concepção da cidade e do papel das crianças inseridas nela. Nesse movimento, a geografia espacial das cidades também exerce um interesse público, que satisfaz necessidades de pessoas e grupos (LEFEBVRE, 2008).

Assim, nesse processo de apropriação do espaço urbano pelas crianças e fortalecimento da cidadania desde a criança e para a criança, a própria "praça" torna-se um local de relações de coexistência com o diferente. Assim, as praças podem tornar-se território de uso e pertencimento do bairro, com a ocupação dos moradores das redondezas, efetivando o direito de todos à cultura e ao lazer. Isso representa um espaço para as crianças: um espaço para brincar. Os brinquedos disponíveis nessas praças, geralmente dentro de cercados, são procurados especialmente nos finais de semana, quando a sua apropriação por pais e filhos é mais intensa. A existência dessa possibilidade é indispensável para a mediação entre crianças e a necessidade de as crianças construírem sua própria criticidade, criatividade e encontrarem meios de se expressarem, e as brincadeiras são fundamentais nesse processo (NASCIMENTO, 2006).

Dessa forma, é curioso perceber como o próprio ato de brincar pode ser encarado como uma tática de apropriação do espaço infantil, pois as brincadeiras possibilitam colocar a criança como o agente protagonista da ação. Assim, as crianças vão desenvolvendo métodos que, em um mundo assumido pelos adultos que não as têm como protagonistas, permitem que elas se desloquem pelos espaços públicos, o que se torna uma experiência muito valorizada (ROCCO, 2015). 
E é nessa reapropriação das praças que o citadino pode ver e ser visto: novamente a cidadania entra em cena, atuando como um exercício sustentado nas ações voltadas ao bem-estar da coletividade. Por meio disso a cidade pode, efetivamente, ocupar esse mencionado lugar de coesão e trocas, dentro de um contexto de diversidade e multiplicidade (BORJA, 2005).

A escola é uma "estreia" da vida pública. É a primeira apropriação do espaço público pelas crianças. No momento em que a escola ultrapassa os limites do "enclave fortificado" de Caldeira (2000), ela pode se transformar em uma poderosa ferramenta de envolvimento da criança com o espaço urbano. É no trajeto da escola para casa/de casa para a escola que a criança poderá criar e desenvolver um sentimento de pertença com a cidade em que reside.

Ao mesmo tempo que a modernidade introduziu a escola como condição de acesso à cidadania, realizou um trabalho de separação das crianças do espaço público. As crianças são vistas como os cidadãos do futuro, mas, no presente, encontram-se afastadas do convívio coletivo, salvo no contexto escolar, e resguardadas pelas famílias da presença plena na vida em sociedade (SARMENTO; FERNANDES; TOMÁS, 2007, p. 188, grifo do autor).

Esse trajeto, mais do que meramente um período de deslocamento, pode ser utilizado como ferramenta de envolvimento da criança com espaços urbanos. Para tanto, a primeira atitude a tomar é desenvolver no jovem um sentimento de pertença e envolvê-lo com a cidade.

A apropriação do espaço urbano pelas crianças, portanto, permite uma ressignificação do próprio espaço urbano, questionando a dicotomia entre público e privado, possibilitando que ambas as esferas não sejam mais encaradas como âmbitos separados, mas sim compreendidas como complementaridade e união nas diferenças.

Aqui, o conceito de cidadania implica um desafio para as cidades: fazer de seus lugares, tanto centrais quanto periféricos, de seus bairros e espaços públicos, bem como da autoestima de seus habitantes, um produtor de sentido à vida cotidiana. Ao mesmo tempo, a cidadania é construída na sociedade como um espaço de valores, ações e instituições que integram os indivíduos (DIAS; FERREIRA, 2015, p. 127).

É claro que não se pode ignorar a baixa autonomia das crianças nesse contexto, uma vez que a sua maior autonomização depende muito da sua relação com os pais, de forma que a estrutura espacial e social da cidade influencia muito nesse processo de reconhecimento e identificação com o ambiente urbano.

No momento em que se reconhece a rua como um território que pode ser explorado, no entanto, a criança adquire autonomia para questionar seu papel apenas como coadjuvante e se tornar protagonista da construção de uma nova realidade brasileira. Assim sendo, é indispensável garantir a participação infantil na vida da cidade, para que isso impulsione o exercício da sua cidadania, para que num futuro imediato participe ativamente dos processos decisórios, no uso coletivo e apropriação dos espaços públicos urbanos.

\section{Considerações Finais}

Talvez seja hora de voltarmos nossos olhares para o velho sonho de uma cidade meIhor, que foi sufocado pela industrialização e crescimento descontrolado de subúrbios, que se tornam a visão triunfante nas cidades. O problema da segurança, ou da ausência dela, 


\section{Democracia}

substituiu as questões envolvendo o sagrado de outras épocas (KOTKIN, 2012), criou restrições de circulação pelas cidades e acabou separando o sujeito e cidadão (citadino) da cidade.

A cidade, dessa forma, deve deixar de ser encarada como um não lugar, um local que deve ser evitado, apesar dos seus inúmeros problemas, mas sim um espaço que deve ser ressignificado, para que as crianças também sejam incluídas nele. Isso leva a questionar: Qual é o entretenimento que tem sido destinado às crianças? Muito embora sejam inegáveis as transformações pelas quais a infância contemporânea tem passado, o próprio valor e importância da brincadeira deve ser reavaliado nessa nova ordem social.

Encarando as crianças como atores sociais de transformação, é interessante considerar que as suas demandas têm sido constantemente reprimidas, e sua participação ativa não é considerada para a construção de uma realidade social mais ampla e complexa, por meio de espaços públicos lúdicos voltados ao público infantil.

Felizmente há iniciativas brasileiras, ${ }^{2}$ como o "Parque para Brincar e Pensar", iniciativa da artista e educadora Joana Zatz Mussi, que busca integrar as crianças por meio de brincadeiras, que promove ações com crianças de locais "excluídos do comum", por meio de uma intervenção local, influenciando a construção de uma imaginação coletiva; o projeto "Exploradores de Rua", concretizado pelo coletivo Apé - Estudos em mobilidade - que instigam as crianças a saírem por um passeio guiado por membros do coletivo para desbravar a cidade e conhecer o espaço em que habitam, olhando a cidade de outra maneira e visibilizando, até mesmo, as desigualdades desses espaços.

Tais ações objetivam a redescoberta do espaço público, com a apropriação coletiva das grandes cidades, numa realidade em que espaços públicos estão vazios e espaços privatizados e destinados ao consumo tornam-se centros de convivência. O que se buscou com este trabaIho foi resgatar a cidade como uma comunidade, tirando-a do ciclo exploratório da industrialização, conforme denunciado por Lefebvre (2008).

Finalmente, a criação de espaços públicos para a infância, sem segregações de classe, credo ou raça, e a sua participação cidadã no ambiente da cidade, no qual possam interagir e se desenvolver socialmente, apenas reforça a tese de que os espaços públicos não devem ser criados apenas para ou em função de os pais e adultos, mas devem ser reservados espaços urbanos para a reinvenção da infância, pois acredita-se que tais experiências apenas promovem o enriquecimento das suas vivências, permitindo que as cidades ajam como efetivas cidades educadoras. Esses espaços - apenas reforça-se - devem ser livres, dinâmicos, vivos, e, principalmente, acessíveis a todas as pessoas que dele desejarem fazer parte, permitindo que as crianças sejam desafiadas, descobertas e aventuradas.

\section{Referências}

BAUMAN, Zygmunt. Modernidade líquida. Rio de Janeiro: Zahar, 2001. BORJA, Jordi. La ciudad conquistada. Madrid: Alianza Editorial, 2005.

\footnotetext{
Mais informações disponíveis em: <http://portal.aprendiz.uol.com.br/2015/07/22/por-mais-criancas-na-cidade-por-uma-cidade-das-criancas/> Acesso em: 12 nov. 2016.
} 
CALDEIRA, Teresa Pires do Rio. Cidade de muros: crime, segregação e cidadania em São Paulo. Tradução Frank de Oliveira e Henrique Monteiro. 34. ed. São Paulo: Edusp, 2000.

CASTRO, Lúcia Rabello de (Org.). Infância e adolescência na cultura de consumo. Rio de Janeiro: Nau Editora, 1998.

CRUZ, A. G. C. Espaço urbano e transformações da subjetividade da criança e do adolescente. In: CASTRO, L. R. de (Org.). Infância e adolescência na cultura de consumo. Rio de Janeiro: Nau Editora, 1998.

DaMATTA, Roberto. A casa \& a rua: espaço, cidadania, mulher e morte no Brasil. 5. edição. Rio de Janeiro: Rocco, 1997.

DIAS, Marina Simone; FERREIRA, Bruna Ramos. Espaços públicos e infâncias urbanas: a construção de uma cidadania contemporânea. Revista Brasileira de Estudos Urbanos, Recife, v. 17, n. 3, p. 118-133, set./dez. 2015.

FREITAG, Barbara. Teorias da cidade. Campinas: Papirus, 2006.

KOTKIN, Joel. A cidade: uma história global. Tradução Rafael Mantovani. Rio de Janeiro: Objetiva, 2012.

LEFEBVRE, Henri. A revolução urbana. Tradução Sérgio Martins. Belo Horizonte: Editora UFMG, 2008.

LIMA, Mayumi. A criança e a cidade. São Paulo: Nobel, 1989.

MEKARI, Danilo. Por mais crianças na cidade, uma cidade das crianças. Portal Aprendiz, nov. 2015. Disponível em: $\quad<$ http://portal.aprendiz.uol.com.br/2015/07/22/por-mais-criancas-na-cidade-por-uma-cidade-das-criancas/>. Acesso em: 12 nov. 2016.

NASCIMENTO, Anelise Monteiro. Pesquisando crianças na cidade: interações em um espaço público. In: EDUCERE - CONGRESSO NACIONAL DE EDUCAÇÃO, 6., 2006, Curitiba. Anais... Curitiba: PUCPR, 2006.

ROCCO, Marcelo. A produção do espaço urbano pela perspectiva da criança: entre a brincadeira e o conflito da Favela da Paz em São Paulo. In: ENCONTRO ANUAL DA ANPOCS, 39, 2015, Caxambu, MG, 2015. p. 1-30. Disponível em: <http://www.anpocs.com/index.php/papers-39-encontro/gt/gt09/9522-a-producao-do-espaco-urbano-pela-perspectiva-da-crianca-entre-a-brincadeira-e-o-conflito-na-favela-da-paz-em-sao-paulo/file>. Acesso em: 11 nov. 2016.

SANTOS, Milton. A urbanização brasileira. São Paulo: Hucitec, 1993.

SARMENTO, Manuel Jacinto; FERNANDES, Natália; TOMÁS, Catarina. Políticas públicas e participação infantil. Revista Educação, Sociedade e Culturas, Porto, n. 25, p. 183-206, 2007. 